\title{
Yesterday, today and tomorrow
}

All men by nature desire knowledge Teaching is the highest form of understanding - Aristotle

$\mathrm{T}$ he pioneers of Canadian plastic surgery refined their surgical knowledge and skills almost a century ago, during World War I, giving birth to a specialty that has grown over the years and passing that knowledge to their pupils generation after generation. The surgeons of today are leaders in areas such as craniofacial, microvascular, hand, breast, nerve, transplantation and aesthetic surgery. They have earned worldwide reputations as teachers, researchers and clinicians. Some continue to broaden their expertise in Canada; others have exported their expertise to other countries.

For many years, a wealth of clinical and research work either remained unpublished or occasionally appeared in foreign journals.

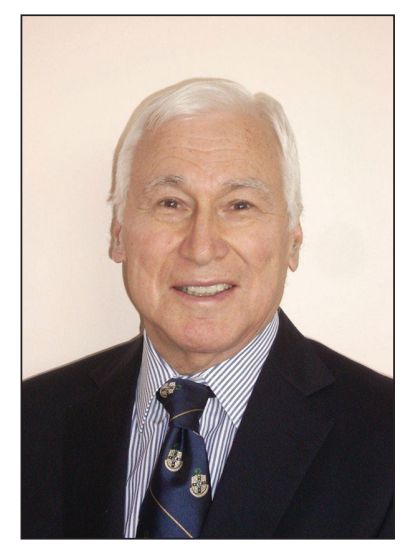

The Canadian Journal of Plastic Surgery was created 18 years ago as a forum for publishing new ideas in plastic surgery.

It is now read worldwide - demonstrated by the many manuscript submissions from all around the world. With its inclusion in PubMed, it is cited by national and international authors.

This exchange of knowledge has created a common bond between us, here in Canada, and our colleagues from around the globe.

To engage our younger colleagues, the leaders of tomorrow, the Journal is moving further into the digital age with increased use of online submissions and features, and social media. The Canadian Society of Plastic Surgeons and its members are taking on an increasing role in the future of the Journal and the future of Canadian plastic surgery.

Peter E Wyshynski MD FRCSC Editor-in-Chief 